\title{
Um grito de negritude: Experiências na formação de leitores/escritores no Programa Mais Educação
}

\author{
Un grito de negritud: Experiencias en la formación de lectores/escritores \\ en el Programa Mais Educação
}

\author{
Agnaldo Mesquita de Lima Junior¹; Dra. Ida Maria Morales Marins²; Santiago Bretanha \\ Freitas $^{3}$ \\ 1agnaldo-mesquita-@ hotmail.com, Universidade Federal do Pampa; \\ 2idamariamarins@gmail.com, Universidade Federal do Pampa; \\ ${ }^{3}$ santiagobretanha@gmail.com, Universidade Federal do Pampa.
}

\begin{abstract}
Resumo
Este estudo tem por objetivo expor o relato de atividades desenvolvidas pelo projeto "Experiência de leitura/escrita: a formação de leitores/escritores", focando-se no sub-projeto "(Di)versificando: diferença na escola", especificamente no módulo I "Um grito de negritude". Este trabalho vem sendo realizado junto ao Programa Mais Educação da Escola Municipal de Ensino Fundamental Marechal Castelo Branco, com o objetivo de oferecer aos alunos uma relação prazerosa com a leitura e produção de diversos textos, focando assim na formação do leitor/escritor de textos literários. Dessa forma, serão apresentadas as referências teóricas e metodológicas utilizadas para ancorar o referido módulo, bem como uma breve descrição das atividades realizadas seguidas de reflexões sobre o trabalho docente.
\end{abstract}

Palavras-Chave: Leitura, Produção textual, experiência docente

\section{Resumen}

Este estudio tiene por objetivo exponer el trabajo realizado pelo proyecto "Experiencia de leitura/escrita: a formação de leitores/escritores", centrando-se en el sub-proyecto "(Di)versificando: diferença na escola", específicamente en el módulo I "Um grito de negritude". Este trabajo fue realizado junto al Programa Mais Educação de la Escola Municipal de Ensino Fundamental Marechal Castelo Branco, con el objetivo de ofrecer a los alumnos un trabajo placentero con la lectura y producción de diversos textos, centrando-se así en la formación del lector/escritor de textos literarios. Desta forma, serán presentadas las referencias teóricas e metodológicas utilizadas para ancorar el referido módulo, bien como una breve descripción de las actividades realizadas seguidas de reflexiones acerca del trabajo docente.

Palabras-Clave: Lectura, Producción textual, experiencia docente

\section{INTRODUÇÃO}

O presente estudo tem por objetivo apresentar as considerações, reflexões e possíveis interpretações sobre a experiência em docência no projeto "Experiência de leitura/escrita: a formação de leitores/escritores". o sub-projeto "(Di)versificando: diferença na escola", 
desenvolvido junto ao Programa Mais Educação da Escola Municipal de Ensino Fundamental Marechal Castelo Branco, e que propõe o trabalho de leitura, interpretação e produção de diversos textos, focando-se no debate dos temas transversais. Foram selecionadas duas turmas A e B, com faixas-etárias entre 10 a 13 anos (turma A) e 14 a 16 anos (turma B). Ainda, este sub-projeto é composto de dois módulos distintos que visam as atividades que abarquem os temais transversais explicitados pelos Parâmetros curriculares nacionais (PCN's). Cabe ressaltar que o trabalho deste sub-projeto faz parte da disciplina de Estágio III, do curso de Licenciatura em Letras- Português/Espanhol, da Universidade Federal do Pampa - Câmpus Jaguarão.

Dentre os muitos problemas enfrentados atualmente em nossa sociedade, a intolerância racial se apresenta (ainda) como objeto central de debate. Muitas políticas públicas surgem hoje como forma de combate ao racismo, porém, ainda mostram-se insuficientes frente à demanda apresentada. Nesse sentido, cresce a consciência da importância da conscientização sobre o tema desde a mais tenra idade e, dessa forma, foca-se na escola como principal instituição de promoção de reflexão e debate sobre o tema. Para isso, dentre outras estratégias, surge a lei de número 10.639/03, que tem por objetivo promover o ensino de conteúdos de “ [...]História da África e dos Africanos, a luta dos negros no Brasil, a cultura negra brasileira e o negro na formação da sociedade nacional, resgatando a contribuição do povo negro nas áreas social, econômica e política pertinentes à História do Brasil.” (BRASIL, 2003, p.01). Ainda na mesma lei, é proposto que todas as disciplinas do currículo escolar devem abordar esse tema, e em especial : “[...] as áreas de Educação Artística e de Literatura e História Brasileiras. (BRASIL, 2003, p.01)”. Ressalta-se então que uma vez que a presente pesquisa visa abordar a leitura de textos literários de forma prazerosa aos alunos, vai ao encontro do proposto pela presente lei no âmbito escolar.

Nesse sentido, este trabalho irá focar-se no módulo 1, denominado "Um grito de negritude", visando o desenvolvimento de atividades que busquem a promoção da igualdade racial. Esse tema encontra-se na orientação da igualdade de direitos proposta pelos PCN's. Segundo esse documento, há de se levar em consideração no momento do ensino, as diferenças "[...]étnicas, culturais, regionais, de gênero, etárias, religiosas, etc.[...]”. (BRASIL, 1997, p.20). Dessa forma a seguir serão apresentados, na sequência, os referenciais teóricos utilizados para a realização do projeto, um breve relato das aulas realizadas e, por fim, algumas reflexões e considerações obtidas através deste projeto. 


\section{REFERENCIAIS TEÓRICOS}

As atividades realizadas dentro deste sub-projeto, baseou-se em três pilares teóricos e/ou metodológicos: A metodologia proposta por Cosson (2011) para o trabalho com textos literários, utilizados nas três primeiras aulas, a teoria de escrita criativa proposta por Di Nizo (2008) visando o desenvolvimento da escrita de forma prazerosa e a apresentada por Ruiz (2010), que versa sobre a correção de textos e que posteriormente foi adaptada pelos alunos executores do projeto de forma a contribuir com novas aprendizagens aos alunos.

\section{1. "A sequência expandida"}

Segundo Cosson (2011), esta é “"[...] uma proposta de ensino da leitura literária na escola básica." (p.11) Por isso, apresentamos esta metodologia de trabalho com textos literários, por acreditar que ela poderia solucionar as inquietações dos professores além de promover a aprendizagem plena da literatura. Esta metodologia baseia-se em sete etapas de exercícios com o texto de forma a buscar um melhor entendimento dos sentidos do texto: motivação, introdução, leitura, primeira interpretação, contextualização, segunda interpretação e expansão. Partindo do proposto por Bettelheim (2011) pode-se perceber que a mente das crianças “[...] contém um conjunto de impressões em rápida expansão que são com frequência mal ordenadas e só parcialmente integradas[...]”. Cabe ressaltar que, conforme posto por Cosson (2011), “[...] a matéria constitutiva do mundo, é, antes de mais nada, a linguagem que o expressa.”(p.15). Dessa forma, a escolha desta metodologia surge com a forma de organizar da melhor forma possível a leitura desses alunos, de forma a uma melhor compreensão dos textos lidos e também da promoção de melhores relações entre esses textos e sua realidade, resultando assim em novas reflexões. Adiante, juntamente com a descrição do trabalho realizado, será explicada cada etapa apresentada.

\section{2 "A motivação de aprender"}

Di Nizo (2008) mostra que o trabalho de escrita é cansativo e trabalhoso, porém, prazeroso quando se retoma o gosto pela produção. Assim, a mesma autora ressalta que é 
necessário retomar o gosto pela leitura, pois a produção textual é uma habilidade “[..]orgânica, e não mecânica.” (p.37). Podemos entender então que somente treinar a escrita não é suficiente, é necessário tomar gosto por ela para que assim se desenvolvam aptidões necessárias para o seu desenvolvimento. Além disso, Ramos (2002) ressalta que é “[...]que se aprende a usar uma língua.” (p.20-21). Partindo desse preceito, percebe-se que além do desenvolvimento pelo gosto, é necessário que os alunos também pratiquem e falem sobre suas produções. Esta importância é ressaltada por Cosson (2011), ao afirmar que "praticamente todas as transações humanas de nossa sociedade letrada passam, de uma maneira ou de outra, pela escrita[...] (p.16). Dessa forma, os alunos executores do projeto basearam-se nesse preceito para desenvolver o gosto pela escrita e a competência produtiva junto aos alunos participantes do projeto, uma vez que essa competência é de extrema importância em nossa sociedade atual.

\section{2. "A correção textual-interativa"}

Esta proposta apresentada por Ruiz (2010) consiste em pequenos bilhetes junto à produção do aluno com o intuito de que o aluno possa ter feedbacks sobre como está indo sua produção. Segundo a própria autora, estes bilhetes falam muito mais que simples problemas textuais, mais também de aproximar o professor do aluno, dando liberdade ao professor de elogiar o trabalho do aluno, cobrar o que não foi feito, apontar aspectos relevantes na escrita e etc. Além disso, Ramos (2002), afirma que "quem quiser avaliar produção de texto deverá treinar produção de textos" (p.02). Nesse sentido, é possível inferir que os acadêmicos a partir de suas próprias experiências dentro de seu curso de graduação estão aptos a realizar a correção da produção de seus alunos.

Assim, os alunos do projeto puderam em suas produções observar o trabalho de construção textual, refletindo sobre o que estão produzindo e tendo feedbacks sobre seus textos. Além disso, esta estratégia possibilita minimizar os problemas de produção dos alunos, uma vez que, segundo Ramos (2002), propicia o contato com a norma padrão da língua, porém, sem tirar o reconhecimento de sua própria norma e de seus saberes locais

\section{DESCRIÇÃO DAS ATIVIDADES}


Visto que o projeto funcionava em três dias semanais, com uma hora/aula por dia, e que cada módulo levaria duas semanas (seis horas/aula por turma), o projeto foi pensado de forma que as três primeiras aulas ocorressem segundo a metodologia de trabalho proposta por Cosson (2011) e as três aulas seguissem perpassassem pela produção inicial, o processo de correção/reescrita e por fim, a produção final. As turmas eram de faixas etárias diferentes, fazendo com que as atividades planejadas fossem diferentes para cada turma. Assim, presente módulo foi realizado da seguinte forma:

Aula 1: As primeiras etapas trabalhadas foram a de Motivação e Introdução. Essas etapas têm por objetivo respectivamente: inserir o aluno no contexto do livro a ser lido e apresentar o autor e as similaridades da obra a ser lida. Nessa aula, para ambas as turmas foi pensada a mesma atividade. Os professores convidaram duas representantes do coletivo feminista margaridas para realizar uma oficina de confecção de bonecas A palavra "abayomi”, de origem iorubá, designa uma boneca negra, tendo por significado "aquele que traz felicidade ou alegria (abayomi quer dizer encontro precioso: abay=encontro e omi=precioso); nome comum em toda a África, principalmente na África do Sul, embora seja observado com frequência no norte da África e, mais raramente, no Brasil. Uma narrativa altamente disseminada, porém, sem comprovação científica, conta que as crianças, em estando nos navios negreiros, choravam pela realidade estranha que se colocava a sua frente; as mães, como forma de acalantá-las rasgavam suas próprias roupas e faziam pequenas bonecas, feitas de retalhos e nós; bonequinhas estas que eram entregues às crianças como forma de lhes amenizar o sofrimento; Assim, julgou-se interessante o trabalho com tais artefatos, por acreditar haver uma representatividade da cultura africana dentro destas bonecas. Na segunda parte da aula, os professores introduziram a temática da próxima aula falando sobre os livros escolhidos.

Aula 2: As etapas de leitura, primeira interpretação e contextualização. Os objetivos destas etapas são: propriamente ler o livro trabalhado, fazer uma discussão geral do texto e por fim contextualizar a obra à seu tempo e sua história. Os livros escolhidos para esta etapa. Nesse caso, foram pensados livros diferentes para cada turma. A turma A por ser de uma faixa etária menor, realizou a leitura do livro "O cabelo de Lelê" da escritora brasileira Valéria Belém; já a turma B,trabalhou com o livro "As tranças de Bintou", de autoria da francesa (de ascendência senegalesa) Sylviane A. Diouf. Logo após a leitura de cada livro com a respectiva turma, os professores encaminhavam uma discussão sobre a leitura realizada, a fim de trabalhar alguns pontos do texto. 
Aula 3: As etapas trabalhadas foram as de segunda interpretação e expansão. Essas etapas objetivam que o aluno faça uma interpretação mais a fundo de um dos aspectos do texto e realizar relações entre a obra lida e o contexto real de vivencia do aluno. Primeiramente, os professores fizeram em cada turma uma breve discussão sobre o que foi lido no texto e o que foi trabalhado nas outras etapas. Logo em seguida, foram propostas uma tarefa diferente para cada turma. A turma A trabalhou com comerciais de TV que abordassem o fato da libertação dos cachos como forma de liberação da cultura afro-brasileira; a turma B realizou uma atividade com a música "Boa esperança" do Rapper Emicida. Cabe ressaltar que em ambos os casos, os professores realizaram intervenções a fim de guiar o entendimento e promover relações entre o que foi discutido anteriormente e o que está sendo inferido nos vídeos e na música.

Aula 4: Nesta aula, será realizada a produção inicial do aluno. Neste módulo, foi escolhido o gênero Poema. Desta forma, cada aluno deveria produzir um poema que abordasse a questão do negro, relacionando com as discussões, atividades realizadas e o texto lido. Assim, primeiramente foi apresentado o gênero trabalhado, bem como sua forma e suas especificidades. Em seguida, foi pedido aos alunos que escrevam sua primeira versão de um poema. Os professores auxiliavam e tiravam dúvidas sempre que necessário.

Aula 5 : Etapa de correção das atividades e conversas direcionadas sobre a produção dos alunos. O objetivo era que o aluno pudesse refletir sobre sua produção se focando nos pontos positivos e negativos de sua produção. Nesta etapa, os professores realizaram as correções prévias em casa e encaminharam bilhetes sobre como cada aluno estava se saindo em suas produções. Na sala, porém, os alunos eram chamados um por vez a mesa dos professores para debates questões referentes à produção de seus textos.

Aula 6: Nesta última aula, o objetivo era que os alunos reescrevessem suas produções, após as reflexões realizadas na aula anterior. As produções foram feitas em folha separada, com o objetivo de deixar registradas essas produções e mais pra frente, tentar publicá-las de alguma forma.

\section{CONSIDERAÇÕES FINAIS}

Dessa forma, percebe-se que o trabalho com as metodologias escolhidas, implica em uma boa forma de aplicação e trabalho com os temas propostos, além de se concretizar em atividades interessantes e prazerosas aos alunos. Assim, a metodologia empregada 
possibilitou, conforme posto por Cosson (2011), fazer os alunos significarem suas leituras para si e para as comunidades nas quais estão inseridos.

No que diz respeito aos conteúdos, os temas vão ao encontro dos PCN's, uma vez que ao propor atividades que vise à promoção do respeito pelas diferenças raciais, contribui-se para a sociedade em que se estão inseridos, já que conforme posto em Brasil (1997):

Para viver democraticamente em uma sociedade plural é preciso respeitar os diferentes grupos e culturas que a constituem. A sociedade brasileira é formada não só por diferentes etnias, como por imigrantes de diferentes países. Além disso, as migrações colocam em contato grupos diferenciados. (p.27)

Assim, demonstra-se que a escola deve ser instituição central no desenvolvimento da cidadania e no respeito na sociedade, percebida ainda como em Brasil (1997), como local de aprendizado, debate, trocas de experiências e convívio com as diferentes formas de viver, pensar, agir e ser.

Ao professor cabe também a reflexão sobre alguns aspectos de sua formação e de sua vida pessoal/social, visto que as temáticas são de temas que geralmente não são abordados nos currículos das licenciaturas, apesar de estarem diariamente no debate das comunidades escolares. Gomes (2005) afirma que “Ainda encontramos muitos(as) educadores(as) que pensam que discutir sobre relações raciais não é tarefa da educação. É um dever dos militantes políticos, dos sociólogos e antropólogos.” (p.146). Ainda, essa autora ressalta que trabalhar as dimensões cidadãs e culturais não resultam em transformá-las em conteúdos didáticos, mas sim em abordá-las durante o desenvolvimento desses conteúdos. Percebe-se então que o professor, nesse sentido, deve ser um cidadão consciente e ciente dos problemas e questões enfrentadas pela sociedade na qual está inserida.

Além disso, faz-se necessário pensar, conforme posto por Ramos (2002), a figura exercida pelo professor na produção textual de seus alunos, de modo a acabar com o dialogismo do professor como "revisor e destinatários do texto dos alunos" (p.16). É preciso pensar alternativas de produções para além das paredes da sala de aula, fazendo com que as reflexões ali realizadas tomem as ruas e se multipliquem em novas reflexões, promovendo assim significativas contribuições para a sociedade.

Em outro ponto, cabe pensar o papel de reforçar protagonismos negros dentro das escolas, uma vez que o trabalho com este tema resulta também em visibilidade aos negros dentro do processo escolar. Porém, conforme mostra Andrade (2005),

Uma Oficina não é suficiente para crianças brancas ou negras reconhecerem-se como seres diferentes, com histórias diferentes, nem superiores nem inferiores. Uma 
Oficina é um momento de reflexão que deve ser bem conduzida pelo(a) facilitador(a), de modo que as crianças saiam dela fortalecidas - e não envergonhadas, brancas ou negras - para continuar uma convivência onde os estereótipos consigam ser corrigidos e ambos os grupos vivam com mais saúde, livres do racismo, já que o racismo destrói quem o manifesta e quem é vítima. Uma Oficina pode dar seqüência a tantas outras, quando convier. Mãos às obras, literalmente! (p.122)

Percebe-se se assim que esse trabalho iniciado precisa de continuidade por parte da escola para que assim seus alunos possam refletir mais sobre esse tema. Do contrário, será apenas mais uma atividade isolada, que abordará um tema e que poderá suscitar a curiosidade de seus alunos, sem garantir porém, grandes resultados. $\mathrm{O}$ trabalho reflexivo deve ser feito em conjunto entre os alunos, professores e toda comunidade escolar através de diversas atividades.

Por fim, cabe pensar que o trabalho com literatura na escola, principalmente com textos que exprimem algum sentido de "realidade", pode, conforme mostrado por Bettelheim (2007), “[...] fornecer alguma informação interessante e frequentemente útil.”(p.79). Assim, ao instrumentalizar o aluno com debates sobre temas do cotidiano, estaremos contribuindo em sua vida pessoal, uma vez que esses conhecimentos serão utilizados por ele na elaboração de alguma outra atividade ou em algum aspecto de sua vida.

\section{Referências}

ANDRADE, I. P. Construindo a auto-estima da criança negra. In: MUNANGA, K. (Org). Superando o Racismo na escola. Brasília: Ministério da Educação, Secretaria de Educação Continuada, Alfabetização e Diversidade, 2005.

BETTELHEIM, B. A psicanálise dos contos de fada. Tradução de Arlene Caetano. São Paulo: Paz e Terra, 2011. 26ª reimpressão.

BRASIL, Secretaria de Educação Fundamental. Parâmetros curriculares nacionais : apresentação dos temas transversais: ética. Brasília: MEC/SEF, 1998.

Lei 10.639 de 09 de janeiro de 2003 que altera a Lei 9.394, de 20 de dezembro de 1996, que estabelece as diretrizes e bases da educação nacional, para incluir no currículo oficial da Rede de Ensino a obrigatoriedade da temática "História e cultura Afro-Brasileira", e dá outras providências. Brasília, 2003.

COSSON, R. Letramento literário: teoria e prática. São Paulo: Contexto, 2006. 
GOMES, N. L. Educação e Relações Raciais: Refletindo sobre Algumas Estratégias de Atuação In: MUNANGA, K. (Org). Superando o Racismo na escola. Brasília: Ministério da Educação, Secretaria de Educação Continuada, Alfabetização e Diversidade, 2005.

DI NIZO, R. Escrita criativa: o prazer da linguagem. São Paulo: Summus, 2008.

RAMOS, J. M. O espaço da oralidade na sala de aula. São Paulo: Martins Fontes, 2002. $3^{\text {a }}$ tiragem.

RUIZ, E. D. Como se corrige redação na escola. Campinas: Mercado de Letras, 2001. 